\title{
Genetics of Obesity
}

\section{Iffet Bircan}

Akdeniz University Medical School, Department of Pediatric Endocrinology, Antalya, Turkey

\section{Keywords: \\ obesity, genetic, gene, \\ mutation \\ Received: 30 October, 2008 \\ Accepted: 21 November, 2008 \\ Corresponding Author: \\ Iffet Bircan \\ Akdeniz University Medical \\ School Department of \\ Pediatric Endocrinology \\ Antalya, Turkey \\ E-mail: ibircan@akdeniz.edu.tr}

\section{ABSTRACT}

The genetic basis of predispositon to obesity has been recognised for a long time. Several single gene-defects in rodents and humans cause the development of obesity. However these are extremely rare and an increase in genetic defects is insufficient to explain the substantial increase in the prevalance of obesity over the past two decades. There is a continuing search for obesity genes. Although single gene mutations in humans are not a major cause of the current obesity epidemic, they support the importance of these genes in the regulation of energy balance.

This review presents some of these genetic mutations that result in obesity.

Conflict of interest: None declared

Obesity presents as a disorder of the mechanisms of energy balance in the body.

Although predisposition to obesity is partly determined by genetic factors, an obesogenic environment is required for the phenotypic expression. Factors regulating body weight are listed in Table 1.

The increase seen during the last thirty years in the prevalence of obesity among children and adults is accepted to be a consequence of the increase in the consumption of energy-rich foods with reduction in physical activity, i.e., a change in the conditions that the genome has 'learned' and 'adapted to' a long time ago.

The genetic basis of predispositon to obesity has been recognised for a long time. Body weight, like height, is passed on genetically. The genetic make up of monozygotic twins is 100\% identical, and despite separation in life they have very similar BMIs (body mass index). It has also been shown in monozygotic twins that environmental effects are more effective before the age of 10, while the effects of genetic factors gain prominence in later years. The body fat content of adopted children shows a better correlation with that of their biological parents. Studies in twins have shown that $75-80 \%$ of body fat is subject to genetically controlled factors, the remainder being determined by environmental factors.

Studies that have best shown the interaction of the environment and the genetic make up are those carried on the Pima Indian communities. While obesity reached levels of severity in the communities living in the USA, there was a much smaller incidence of obesity among those living in the rural Sonora-Mexico border and surviving on physical labour and limited nutrition.

Genome-wide scans in obese adults of different ethnic groups have revealed differences in the make up of the linking zones between chromosomes 2p, 7q, 10p and between $\mathrm{q}$ and $\mathrm{p}$. The scans in obese children have shown that an association with a gene locus on chromosome 10p is the most consistent genetic finding.(1, 2, 3, 4, 5)

The results of comparative investigations on the mutations in the homologous candidate obesity genes of the human adult and of mice have shown 
the significance of the pathways of energy balance in obesity.

\section{THE LEPTIN-MELANOCORTIN PATHWAY}

Leptin is released from the adipocytes in amounts proportional to the body weight content. Passing the blood-brain barrier, leptin binds with its receptors on the neurons with resultant effects on body energy balance, which in the long term is a decrease in appetite and an increase in thermogenesis, both leading to a decrease in adiposity. The hypothalamic arcuate nucleus (ARC) neurons are the primary responders to the changes in the body energy depots, bringing about regulation of appetite and of the energy homoestasis.

\section{PR0-0PIMELANOCORTIN (POMC)}

While the anorectic peptide $\alpha$-melanocyte stimulating hormone (MSH) and the cocaine and amphetamine-related transcript (CART) are synthesized by the 'POMC-neurons' of the hypothalamic ARC, another group of neurons produce neuropeptide-Y (NPY) and the agouti-related protein (AGRP), which are orexogenic peptides. AGRP is a powerful melanocortin-3 receptor (MC3R) and melanocortin-4 receptor (MC4R) antagonist. Both NPY and AGRP neurons cause increased food consumption and reduce energy expenditure, acting in the opposite direction to the POMC-neurons. These two groups of neurons in the ARC also influence the actions of other second-order neurons in the central nervous system (CNS), especially those in the lateral hypothalamus and the paraventricular nucleus causing the expression of neuropeptides involved in energy homoestasis.

In 1997 GOOS (Genetics of Obesity Study) was initiated, aiming to determine the candidate genes regulating the body weight in childhood obesity. This cohort study covered 2500 obese individuals under the age of ten, with a family history of obesity and a body mass index (BMI-SDS) of >3. (3)

\section{Table 1: Factors regulating body weight*}

Short term weight regulators

- Cholecystokinin (satiety)

Ghrelin (orexigenic)

Peptide YY (anorexigenic)

Long term weight regulators

Neuropeptide Y (appetite promoter)

Agouti-related protein

Insulin

Leptin

POMC (appetite suppressor)

MC4R

$\mathrm{PCl}$

Abbreviations explained in the text

\section{CONGENITAL LEPTIN AND LEPTIN-RECEPTOR DEFICIENCY}

This condition was first described in 1997, in two obese children who were cousins and offsprings of interfamily marriage in Pakistan. Both chidren had unmeasurable serum leptin levels and a homozygotic frame-shift mutation ( $\Delta$ G133) on the OB gene. Subsequently, 5 more cases in Pakistan with the same mutation were identified. Also, a homozygotic missense mutation has been detected in three individuals from a large Turkish family.(9)

The first homozygotic leptin-receptor gene mutation was described in 1998 in 3 adult members of an inbred Algerian family.

The phenotypic presentation of leptin and of leptin-receptor deficiency are clinically similar. Birthweight is normal but there is severe obesity with rapid weight gain from the early months postnatally with excess amount of adiposity on the body and the limbs. All cases are hyperinsulinaemic, with the development of Type-2 diabetes mellitus (T2DM) in some. All exhibit excessive appetite for foods of high calory content with aggressive behaviour on lack of food to consume. There is concurrent hypothalamic hypothyroidism and hypogonadotropic hypogonadism and absence of normal pubertal changes. Although normal linear growth and normal IGF1 levels are observed during childhood, final height is short since there is no acceleration 
in growth which occurs with normal pubertal development. Mortality from severe infections due to reduction in T-cell counts and functions have been reported.

Treatment with recombinant human leptin $(0.01 \mathrm{mg} / \mathrm{kg}, \mathrm{sc})$ of three children has yielded good results, with normalisation of the excessive appetite. Similar good results were obtained in three Turkish adults. Leptin treatment led to improvement in thyroid functions as well as normalising the pulsatile gonadotropin secretion and has resulted in the appearance of secondary sex characteristics.(11)

However, a 28-week treatment of obese patients with supraphysiological doses of leptin $(0.1-0.3 \mathrm{mg} / \mathrm{kg})$ has not yielded results of any significance.(1)

\section{POMC DEFICIENCY}

POMC deficiency was first demonstrated in 1998 by Krude et al.(8) in 2 and then in 3 cases. This was followed by 6 cases reported by Farooqi et al.(6) These were homozygotic or combined heterozygotic cases. One of these patients died from hypocortisolaemia due to ACTH deficiency and prolongued icterus with evidence of sepsis. Although POMC deficient patients were reported to respond to cortisol treatment, they eventually developed hyperphagia and severe obesity. The pallor and red hair observed in these patients have been attributed to the dysfunction of the MC1R. However, the dark hair coloration of 6 Turkish patients indicates a genetic difference from the European children.

\section{POMC HAPLOINSUFFICIENCY}

Krude et al.(8) have reported loss of one POMC allele with BMI SDS values at the upper limit of normal in the parents and heterozygotic relations of homozygotic patients with this condition. Farooqi et al.(6) have found the prevalence of obesity and overweight to be high in 7 homozygotic and 12 heterozygotic cases from the same Turkish family. They have concluded that heterozygotic point mutations in POMC, $\alpha$ and $\beta-\mathrm{MSH}$ increased the risk of obesity.(3)

\section{PROHORMON CONVERTASE-1 (PC1) MUTATIONS}

Biologically inactive prohormones and neuropeptides are converted to active-forms by the serin endoproteases. PC1 and 2 are expressed in neuroendocrine tissues and activate proinsulin, proglucagon and POMC. Combined heterozygotic PC1 mutation has been reported in a severely obese patient. In 2 other patients with combined heterozygotic mutations small intestinal dysfunction has been reported.(3)

\section{MC4R DEFICIENCY}

Heterozygotic MC4R mutations were first reported in hereditary obesity by two different groups of investigators in 1998 and has since been reported in different ethnic communities. A prevalence of 5-6\% had been reported in the 2500 patients covered by GOOS. Hyperphagia starting at the age of one; an increase in the muscle and the skeletal mass together with adipose tissue mass were noted in 150 patients with MC4R deficiency. These patients are noted to have a bony appearance. Linear growth is increased in early childhood as a consequence of hyperinsulinaemia rather than dysfunction in the growth hormone $(\mathrm{GH})$ axis. Obesity was more severe in homozygous patients. In the MC4R knock-out mouse model a similar early hyperinsulinaemia and accelerated linear growth have been reported.

Branson et al. ${ }^{7}$ have carried out genome scans in the MC4R, POMC, $\alpha-M S H$, LEPR encoding regions in 469 cases of morbid obesity with a mean BMI of 44 and a mean age of 42 years and 25 age-matched non-obese controls. MC4R mutations were identified in $5.1 \%$ of the obese and 1\% of the controls. All carriers ate when not hungry, with at least two occasions of binge-eating per week, and felt sorry, guilty and depressive for having gone out of control in their eating habits. The habit of binge-eating was present in 14\% of 
the obese without MC4R mutation but in $100 \%$ of those with mutations. Although MC4R deficiency is regarded as the most frequently observed form of monogenic obesity in man, there are studies showing the absence of obesity in some heterozygote carriers, a finding which suggest the multifactorial character of obesity, subject to genetically and environmentally determined processes.

As yet there is no specific mode of treatment for MC4R deficiency. In the heterozygotic patient with one normal allele, the use of a MC4R agonist with small molecular structure might be the treatment choice in the future. $(6,7,8)$

\section{NEUROTROPIN RECEPTOR TROPOMYOSIN-RELATED KINASE B (TrkB) MUTATIONS}

Development of the brain-derived neurotrophic factor (BDNF) regulate the life span and differentiation of neurons. These neurons have a high affinity for the TrkB receptors.

Lastly, the regulation of body weight is thought to be achieved by the down regulation of $\mathrm{BDNF}$ in hunger states. In wild-type mice given BDNF weight loss due to lowered phagia has been observed.(3)

In conclusion it can be said that despite the mapping of the obesity related genes, a genotype with high penetrance and high risk has not yet been identified. The three genome-wide scans reported so far indicate chromosomes 2p, 3q 5p, 6p 7q,10p and 20q as the possible sites of the candidate genes. Although over 70 genes have been reported to have association with obesity; these have not been strong or consistent associations. Obesity outside monogenic disorders can be possibly classified as obesity with strong genetic predisposition, weak genetic predisposition and genetic resistance.

\section{REFERENCES}

1. Alemdezah R, Rising R, Lifshits F. Obesity in children. In: Pediatric Endocrinology. Lifsshitz F.(ed) 5th ed, Informa Healthcare USA Inc, New York, 2007;11-17.

2. Farooqi IS. Genetic and hereditary aspects of childhood obesity. Best Pract Res Clin Endocrinol Metab 2005:19:359-374. [Abstract / PDF]

3. Farooqi IS. Monogenic human obesity. Front Horm Res 2008:36:1-11. [Abstract]

4. Tunçbilek E. Obezite genetik bir hastalık mıdır? Çocuk Sağlığı ve Hastalıkları Derg 2005:48:101-108. [Abstract / Full Text / PDF]

5. Millington GWM. The role of proopiomelamocortin (POMC) neurons in feeding behaviour. Nutrition \& Metabolism 2007;4:18-22. [Abstract / Full Text / PDF]

6. Farooqi SI, Keogh JM, Yeo GS, Lang EJ, Cheehtam T, O'Rahilly S. Clinical spectrum of obesity and mutations in the melanocortin 4 receptor gene. N Engl J Med 2003;348:1096-1103. [Abstract / Full Text / PDF]

7. Branson R, Potoczna N, Kral JG, Lentes KU, Hoehe MR, Horber FF. Binge eating as a major phenotype of melanocortin 4 receptor gene mutations. N Eng J Med 2003;348:1096-1103. [Abstract / Full Text / PDF]

8. Krude H, Biebermann H, Schnabel D, et al. Obesity due to proopiomelanocortin deficiency: three new cases and treatment trials with thyroid hormone and ACTH 4-10. J Clin Endocrinol Metab 2003;88:4633-4640. [Abstract / Full Text / PDF]

9. Özata M, Özdemir IC, Licinio J. Human leptin deficiency caused by a missense mutation: multiple endocrine defects, decreased sympathetic toneand immune system disfunction indicate new targets for leptin action, greater central than peripheral resistance to the effects of leptin, and spontaneous correction of leptin mediated defects. J Clin Endocrinol Metab 1999;84:3686- 3695. [Abstract / Full Text / PDF]

10. Farooqi IS, Jebb SA, Langmack $G$, et al. Effects of recombinant leptin therapy in a child with congenital leptin deficiency. N Eng J Med 1999;341:879-884. [Abstract / Full Text / PDF]

11. Gibson WT, Farooqi IS, Moreau M, DePaoli AM, Lawrence E, O'Rahilly S, Trussell RA. Congenital leptin deficiency due to homozygosity for Delta $133 \mathrm{G}$ mutation: another case and evaluation of response to four years of leptin therapy. J Clin Endocrinol Metab 2004;89:4821-4826. [Abstract / Full Text / PDF] 